\title{
STUDIES ON THE CHEMOTHERAPY OF THE HUMAN MALARIAS. V. THE ANTIMALARIAL ACTIVITY OF QUINACRINE 1, 2,
}

\author{
BY JOHN V. TAGGART, DAVID P. EARLE, JR., ROBERT W. BERLINER, WILLIAM \\ J. WELCH, 4 CHARLES G. ZUBROD, 4 JOSEPH W. JAILER, 4 BEATRICE \\ H. KUHN, JACKSON NORWOOD, 5 AND JAMES A. SHANNON \\ (From the Department of Medicine, New York University College of Medicine, and the \\ Research Service, Third [New York University] Medical Division, \\ Goldwater Memorial Hospital, New York City)
}

(Received for publication March 12, 1947)

\section{INTRODUCTION}

Although quinacrine has been used widely in the suppression and treatment of malaria since 1931 , its usage up to and during the early years of the war was largely empirical insofar as dosage regimens are concerned. The development, in 1942 , of simple reliable methods $(1,2)$ for the estimation of quinacrine concentrations in biological materials finally made possible studies of its physiological disposition in terms of measured drug concentrations (3). Information derived from these studies was essential in establishing a basis for the rational usage of quinacrine. Quantitative information concerning its antimalarial activity was equally important in the design of dosage regimens which permit the most effective use of this drug.

The observations reported in this communication are concerned with the suppressive antimalarial activity of quinacrine as measured by its ability to terminate clinical attacks of blood-in-

\footnotetext{
1 The work described in this paper was done under a contract, recommended by the Committee on Medical Research, between the Office of Scientific Research and Development and New York University.

2 A part of the material in this paper has been presented in a Harvey Lecture delivered by Dr. James A. Shannon on Oct. 25, 1945, and also appeared in "Survey of Antimalarial Drugs, 1941-1945," p. 177, J. W. Edwards, Ann Arbor, Mich., 1946. Permission to use Table I has been obtained from the Harvey Society and the editors of the Survey.

3 The authors express their thanks to the Malaria Study Section of the National Institute of Health for editorial assistance and for arrangements in regard to the publication of this paper. They are also grateful to the Abbott Laboratories, E. I. du Pont de Nemours and Company, Inc., E. R. Squibb and Sons, Eli Lilly and Company, Sharp and Dohme, and Wyeth, Inc., for contributing toward the publication costs.

4 Captain, MC, AUS.

5 Lieutenant, MC, USNR.
}

duced vivax and falciparum malaria. The results obtained describe the relationship between oral dosage, plasma quinacrine concentrations, and therapeutic effects. The range of effective plasma drug concentrations in infections due to selected strains of $P$. vivax and $P$. falciparum may be defined. In addition, the data provide a standard of reference for the comparison with quinacrine of promising antimalarial agents whose physiological disposition is similar to that of quinacrine.

\section{PROCEDURE}

The therapeutic tests were performed in accordance with standard procedures previously outlined $(4,5)$. The infections utilized were due to the $\mathrm{McCoy}$ and Chesson strains of $P$. vivax and the $\mathrm{McClendon}$ and Costa strains of $P$. falciparum. Quinacrine was administered by dosage schedules which produce fairly stable plasma drug concentrations during the four-day (vivax) or six-day (falciparum) therapeutic period. The therapeutic results are classified in three groups: Class I, no certain effect; Class II, a temporary suppression of parasitemia and/or fever; and Class III, a "permanent" effect, i.e., an absence of parasitemia for 14 days (vivax) or 21 days (falciparum) followed by a positive reinoculation to demonstrate continuing host-susceptibility to the infection.

In dealing with a drug such as quinacrine, which is localized extensively in tissues, whose rate of metabolic conversion is relatively low and which, consequently, persists in the plasma following the termination of therapy, it is difficult to obtain stable plasma drug levels which are limited to exactly four or six days. This difficulty was taken into consideration in the design of the therapeutic tests and was minimized by the adoption of two conventions. First, equilibrium plasma drug levels were achieved within the first few hours of therapy by the administration of suitable priming doses: Second, the actual period of drug administration was curtailed sufficiently to minimize the persistence of significant plasma drug concentrations beyond the desired four or six days. The mean plasma quinacrine levels presented in the tables are calculated from the levels obtained only during the first four 
or six days after starting therapy. ${ }^{\circ}$ The total oral doses are reported in terms of the free base and include priming as well as maintenance doses.

With potential Class III results, the selection of the time for reinoculation must be based in part on the number of days the drug persists in the plasma. It should be noted that in the standard procedure, the date of reinoculation is fixed with respect to "the day following the last effective plasma drug concentration" (4). Any plasma drug concentration which, when maintained for the period of the therapeutic test, produces a Class II result, is considered "effective." Consequently, follow-up observation periods began on the day when the plasma drug level fell below this value. In certain series of observations, Class II results were obtained at the lowest plasma quinacrine concentrations and the effective level,

TABLE I

The relationship between dosage and plasma concentration of quinacrine and therapeutic effect in four-day tests against blood-induced McCoy vivax malaria

\begin{tabular}{|c|c|c|c|c|c|}
\hline \multirow{2}{*}{ Patient } & \multirow{2}{*}{$\begin{array}{l}\text { Total } \\
\text { dose }\end{array}$} & \multirow{2}{*}{$\begin{array}{c}\text { Mean } \\
\text { plasma } \\
\text { quinacrine } \\
\text { concen- } \\
\text { tration }\end{array}$} & \multicolumn{3}{|c|}{ Class of therapeutic effect } \\
\hline & & & I & II & III \\
\hline $\begin{array}{l}\text { Tra } \\
\text { Wal } \\
\text { Bel } \\
\text { Cra } \\
\text { Chu } \\
\text { Dar } \\
\text { Qui } \\
\text { Wei } \\
\text { Wor } \\
\text { Cas } \\
\text { Daw } \\
\text { Far } \\
\text { Hau } \\
\text { Mis } \\
\text { She } \\
\text { Eic } \\
\text { Mar } \\
\text { Chi } \\
\text { Kas } \\
\text { Sch } \\
\text { Ami } \\
\text { Ash } \\
\text { Ger } \\
\text { Coo } \\
\text { Vit } \\
\text { DeM } \\
\text { Sca } \\
\text { Cou } \\
\text { McB } \\
\text { Saw } \\
\text { Gra } \\
\text { Kel }\end{array}$ & $\begin{array}{c}\text { grams } \\
0.59 \\
0.59 \\
0.59 \\
0.59 \\
0.59 \\
0.72 \\
0.59 \\
0.63 \\
0.59 \\
0.47 \\
0.38 \\
0.38 \\
0.51 \\
0.51 \\
0.38 \\
0.38 \\
0.30 \\
0.38 \\
0.51 \\
0.59 \\
0.38 \\
0.63 \\
0.47 \\
0.30 \\
0.30 \\
0.30 \\
0.38 \\
0.30 \\
0.38 \\
0.21 \\
0.21 \\
0.21\end{array}$ & $\begin{array}{c}\mu g . / L \\
44 \\
39 \\
34 \\
32 \\
31 \\
27 \\
27 \\
26 \\
26 \\
25 \\
24 \\
23 \\
22 \\
21 \\
21 \\
19 \\
19 \\
18 \\
18 \\
18 \\
16 \\
16 \\
16 \\
15 \\
13 \\
13 \\
12 \\
10 \\
8 \\
7 \\
6 \\
3\end{array}$ & $\begin{array}{l}\mathbf{x} \\
\mathbf{x} \\
\mathbf{x} \\
\mathbf{x}\end{array}$ & $\begin{array}{l}\mathbf{x} \\
\mathbf{x} \\
\mathbf{x} \\
\mathbf{x} \\
\mathbf{x} \\
\mathbf{x} \\
\mathbf{x} \\
\mathbf{x} \\
\mathbf{x} \\
\mathbf{x} \\
\mathbf{x} \\
\mathbf{x} \\
\mathbf{x} \\
\mathbf{x} \\
\mathbf{x} \\
\mathbf{x} \\
\mathbf{x}\end{array}$ & $\begin{array}{l}\mathbf{x} \\
\mathbf{x} \\
\mathbf{x} \\
\mathbf{x} \\
\mathbf{x} \\
\mathbf{x} \\
\mathbf{x} \\
\mathbf{x} \\
\mathbf{x}\end{array}$ \\
\hline
\end{tabular}

6 Expression of plasma drug concentrations in other terms, such as the area under the entire plasma drug level curve, or this value divided by the number of days a significant drug level persisted, did not yield a better correlation between plasma level and effect, or between dosage and plasma level. therefore, could not be ascertained. In these cases, the observation period was begun when the plasma drug level had fallen well below that which was estimated to be effective. A delay in the time of reinoculation will not modify the ultimate experimental result since it has been shown that the development of immunity during a period of clinical latency is not appreciable (4).

\section{RESULTS}

\section{Blood-induced vivax malaria}

The effectiveness of various mean plasma quinacrine concentrations, during a four-day therapeutic period, was examined in 32 cases of bloodinduced vivax (McCoy) malaria (Table I). The data reveal that Class III results, a "permanent" interruption of the infection, were observed in 10 subjects at plasma quinacrine concentrations ranging from 44 to $21 \mu \mathrm{g}$. per liter. Class II results, a temporary suppression of parasitemia and/or fever, occurred in 19 cases at concentrations ranging from 27 to $10 \mu \mathrm{g}$. per liter. Four subjects demonstrated no certain. effect from quinacrine administration at concentrations between 8 and $3 \mu \mathrm{g}$. per liter. Therefore, the minimal "effective" plasma quinacrine concentration appears to lie between 8 and $10 \mu \mathrm{g}$. per liter. The division between Class III and Class II results is somewhat less sharply defined. However, if a plasma quinacrine concentration of $25 \mu \mathrm{g}$. per liter is accepted as representing the critical level, then only two of the 29 individuals constituting the two groups may be regarded as exceptions and these fall within a very limited range of plasma quinacrine concentrations (21 to $27 \mu \mathrm{g}$. per liter).

When the various groups of therapeutic effects are considered in terms of the total dose of quinacrine administered, Class III results were obtained with a total dose as low as 0.51 gram, Class II results, with a dose between 0.59 and 0.30 grams, and Class I results, with a total dose as high as 0.38 gram (Figure 1).

Very limited studies were obtained with a second strain of $P$. vivax (Chesson). Two patients with plasma quinacrine concentrations of 26 and $29 \mu \mathrm{g}$. per liter, respectively, maintained for four days, demonstrated only temporary effects. When therapy was extended to six days, two patients with plasma quinacrine levels of 28 and $36 \mu \mathrm{g}$. per liter showed Class III results, while a third, 


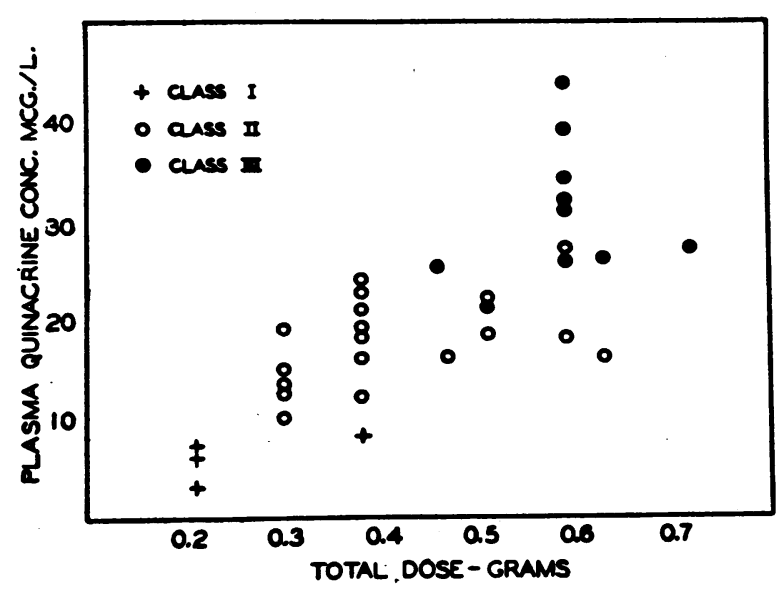

Fig. 1. Relation Between Total Oral Dose and Plasma Quinacrine Level and Antimalarial Effect in P. Vivax (McCoy Strain) Infections

at $14 \mu \mathrm{g}$. per liter, had only a Class II result. These results are in keeping with those obtained during quinine studies in the two strains (4) and indicate a greater resistance of the Chesson strain to quinacrine.

\section{Blood-induced falciparum malaria}

Observations on the effectiveness of quinacrine in blood-induced falciparum ( $\mathrm{McCl}$ endon) malaria were obtained in 24 subjects, stable plasma quinacrine concentrations being maintained for six days. It is apparent from the data presented in Table II that, in relation to plasma quinacrine concentrations, the division between Class III and Class II results was not as sharply defined as in vivax malaria. Plasma quinacrine concentrations ranging from 60 to $48 \mu \mathrm{g}$. per liter resulted in four Class III effects. In the range between 47 and $22 \mu \mathrm{g}$. per liter, there were six Class III and nine Class II results. All five subjects with concentrations below $22 \mu \mathrm{g}$. per liter yielded Class II results. No Class I results were obtained in this series and, consequently, the minimal "effective" concentration was not ascertained.

There is even less correlation between the total oral dose of quinacrine and the therapeutic effect. One Class III result was achieved with a total dose as low as 0.59 gram, while Class II results occurred with total doses ranging from 0.59 to 0.93 gram.

A similar series of observations was obtained in 22 patients with blood-induced falciparum malaria due to a second strain (Costa). The results
TABLE II

The relationship between dosage and plasma concentration of quinacrine and thera peutic effect in six-day tests against blood-induced McClendon falciparum malaria

\begin{tabular}{|c|c|c|c|c|c|}
\hline \multirow{2}{*}{ Patient } & \multirow{2}{*}{$\begin{array}{l}\text { Total } \\
\text { dose }\end{array}$} & \multirow{2}{*}{$\begin{array}{c}\text { Mean } \\
\text { plasma } \\
\text { quinacrine } \\
\text { concen- } \\
\text { tration }\end{array}$} & \multicolumn{3}{|c|}{ Class of therapeutic effect } \\
\hline & & & I & II & III \\
\hline $\begin{array}{l}\text { Ric } \\
\text { Rob } \\
\text { D'I } \\
\text { Smi } \\
\text { Hug } \\
\text { Alu } \\
\text { Mon } \\
\text { DJO } \\
\text { Yea } \\
\text { Mun } \\
\text { Nev } \\
\text { Tek } \\
\text { Mev } \\
\text { Cru } \\
\text { Ker } \\
\text { Par } \\
\text { For } \\
\text { Lad } \\
\text { Sta } \\
\text { Wol } \\
\text { Cia } \\
\text { Cra } \\
\text { Wil } \\
\text { McK }\end{array}$ & $\begin{array}{l}\text { grams } \\
0.85 \\
0.93 \\
0.93 \\
0.93 \\
0.93 \\
0.93 \\
0.93 \\
0.85 \\
0.85 \\
0.93 \\
0.93 \\
0.93 \\
0.85 \\
0.59 \\
0.59 \\
0.85 \\
0.76 \\
0.59 \\
0.80 \\
0.76 \\
0.93 \\
0.76 \\
0.59 \\
0.76\end{array}$ & $\begin{array}{c}\mu g . / L \\
60 \\
52 \\
50 \\
48 \\
47 \\
47 \\
45 \\
38 \\
32 \\
32 \\
29 \\
28 \\
27 \\
27 \\
26 \\
23 \\
22 \\
22 \\
22 \\
21 \\
19 \\
19 \\
14 \\
9\end{array}$ & & $\begin{array}{l}\mathbf{x} \\
\mathbf{x} \\
\mathbf{x} \\
\mathbf{x} \\
\mathbf{x} \\
\mathbf{x} \\
\mathbf{x} \\
\mathbf{x} \\
\mathbf{x} \\
\mathbf{x} \\
\mathbf{x} \\
\mathbf{x} \\
\mathbf{x}\end{array}$ & $\begin{array}{l}\mathbf{x} \\
\mathbf{x} \\
\mathbf{x} \\
\mathbf{x} \\
\mathbf{x} \\
\mathbf{x} \\
\mathbf{x}\end{array}$ \\
\hline
\end{tabular}

TABLE III

The relationship between dosage and plasma concentration of quinacrine and therapeutic effect in four-day tests against blood-induced Costa falciparum malaria

\begin{tabular}{|c|c|c|c|c|}
\hline \multirow{2}{*}{ Patient } & \multirow{2}{*}{$\begin{array}{l}\text { Total } \\
\text { dose }\end{array}$} & \multirow{2}{*}{$\begin{array}{c}\text { Mean } \\
\text { plasma } \\
\text { quinacrine } \\
\text { concen- } \\
\text { tration }\end{array}$} & \multicolumn{2}{|c|}{ Class of therapeutic effect } \\
\hline & & & II & III \\
\hline $\begin{array}{l}\text { Fan } \\
\text { Wad } \\
\text { Che } \\
\text { Bry } \\
\text { Ber } \\
\text { Jor } \\
\text { Bro } \\
\text { Yee } \\
\text { Fre } \\
\text { Bax } \\
\text { Lem } \\
\text { Ron } \\
\text { Sul } \\
\text { Aus } \\
\text { Gwy } \\
\text { Oli } \\
\text { Sim } \\
\text { Par } \\
\text { Mur } \\
\text { AAR } \\
\text { Bar } \\
\text { Kou }\end{array}$ & $\begin{array}{l}\text { grams } \\
0.93 \\
1.10 \\
0.89 \\
1.00 \\
0.89 \\
0.93 \\
0.89 \\
0.89 \\
0.93 \\
0.93 \\
1.01 \\
0.93 \\
0.93 \\
0.93 \\
0.93 \\
0.89 \\
0.93 \\
1.10 \\
0.45 \\
0.89 \\
0.45 \\
0.45\end{array}$ & $\begin{array}{c}\mu g . / L \\
85 \\
82 \\
76 \\
74 \\
68 \\
66 \\
65 \\
61 \\
52 \\
51 \\
50 \\
49 \\
45 \\
34 \\
33 \\
32 \\
28 \\
27 \\
26 \\
20 \\
13 \\
13\end{array}$ & $\begin{array}{l}\mathbf{x} \\
\mathbf{x} \\
\mathbf{x} \\
\mathbf{x} \\
\mathbf{x} \\
\mathbf{x} \\
\mathbf{x} \\
\mathbf{x} \\
\mathbf{x}\end{array}$ & $\begin{array}{l}\mathbf{x} \\
\mathbf{x} \\
\mathbf{x} \\
\mathbf{x} \\
\mathbf{x} \\
\mathbf{x} \\
\mathbf{x} \\
\mathbf{x} \\
\mathbf{x} \\
\mathbf{x} \\
\mathbf{x}\end{array}$ \\
\hline
\end{tabular}


are summarized in Table III. All seven subjects with mean plasma quinacrine concentrations of 65 $\mu \mathrm{g}$. per liter or higher exhibited Class III results. In the range of 61 to $32 \mu \mathrm{g}$. per liter, there were four Class III and five Class II results. All six subjects with plasma quinacrine concentrations of $28 \mu \mathrm{g}$. per liter or lower exhibited Class II results.

From these data it seems likely that the Costa strain of $P$. falciparum is somewhat more resistant to the action of quinacrine than is the McClendon. This is supported by the observation that the lowest total dose of quinacrine which produced a Class III result in Costa falciparum was 0.89 gram as compared with 0.59 gram for the McClendon.

\section{DISCUSSION}

The therapeutic regimens of quinacrine in common usage prior to the war appear to have been constructed so as to produce a therapeutic effect roughly equivalent to that of quinine and at the same time minimize the incidence of toxic reactions. Although the usefulness of quinacrine attained wide acceptance, there were many clinicians who regarded quinacrine as inferior to quinine in the promptness with which an attack of malaria could be terminated. Pharmacological studies have since demonstrated that the extensive tissue localization of quinacrine delays the establishment of equilibrium between plasma quinacrine concentrations and oral dosage. Therefore, plasma quinacrine concentrations tend to be low during the first few days of therapy, unless suitable priming doses of quinacrine are administered (3). It was in consequence of this finding that a revision of therapeutic quinacrine regimens was recommended in 1943.?

The data presented show a positive correlation between plasma quinacrine concentrations and the suppressive antimalarial effects in both vivax and falciparum infections. The plasma quinacrine concentrations and the duration of therapy which are

\footnotetext{
7 According to Circular Letter No. 135, Office of the Surgeon General, Army M. Bull. (No. 65), pp. 216-218, January 1943, the recommended quinacrine dosage for continuous suppression is 0.1 gram once daily on six days of each week. For the treatment of clinical attacks, the recommended dosage is 0.2 gram every six hours for five doses, followed by 0.1 gram three times a day for six days (total 28 grams in seven days).
}

required to interrupt permanently the erythrocytic phase of these infections vary from species to species and strain to strain. However, the data present a quantitative description of these factors in four infections with quite different biological and clinical characteristics. In the light of such information, it should be possible to appraise the adequacy of various quinacrine regimens recommended for the suppression and treatment of malaria.

In McCoy vivax malaria, a mean plasma quinacrine concentration of approximately $25 \mu \mathrm{g}$. per liter, maintained for four days, will terminate an acute clinical attack of malaria, or, in other words, permanently interrupt the erythrocytic phase of the infection. In order to achieve a comparable result in Chesson vivax, a similar concentration must be maintained for six days. Both strains of $P$. falciparum examined appear to be approximately twice as resistant to quinacrine action as the Chesson strain of $P$. vivax, in terms of the plasma quinacrine concentrations required for a given clinical effect.

It has not been possible in such limited studies to determine the lowest plasma quinacrine concentration which exerts a demonstrable suppressive effect in each strain of plasmodium. The minimal effective concentration in McCoy vivax is 10 $\mu \mathrm{g}$. per liter when such a concentration is maintained for four days. Concentrations as low as 9 and $13 \mu \mathrm{g}$. per liter have been shown to exert a definite suppressive action in $\mathrm{McClendon}$ and Costa falciparum, respectively, during a six-day period.

On the basis of these findings, it would appear that currently recommended dosage schedules yield plasma quinacrine concentrations adequate for the routine suppression and treatment of malaria. Subsequent experience has shown this to be so (6). However, it should be noted that the disposition of quinacrine in occasional individuals is such that unusually low plasma quinacrine concentrations are obtained. In these individuals, one may expect that the administration of quinacrine will result in suboptimal clinical responses.

The effectiveness of quinine in vivax and falciparum malarias has been examined in similar studies. Therefore, comparison of quinacrine and quinine in terms of effective plasma drug concentrations and the oral doses required to produce 
a given clinical response is possible. The plasma quinine concentration which will consistently produce a permanent interruption of the erythrocytic phase of $\mathrm{McC}$ oy vivax is approximately 5 mg. per liter (4) as compared with $25 \mu \mathrm{g}$. per liter for quinacrine. A similar proportionality exists between the minimal concentrations of the two drugs which yield a barely detectable suppressive action. Thus, strictly in terms of effective plasma drug concentrations, quinacrine appears to be approximately 200 times as active as quinine in McCoy vivax infections. On the other hand, the oral doses of quinacrine which produce these critical plasma concentrations are only one-third to one-fourth of those required of quinine. A similar situation obtains in infections due to the McClendon strain of $P$. falciparum.

The validity of comparing the antimalarial activities of two agents on the basis of effective plasma concentrations alone may be seriously criticized. Perhaps a better basis of comparison of drugs falling into two quite different categories of physiological disposition is one in which a combination of the two factors is possible. The activity of a drug can be stated in terms of its "effective" concentration and its effective dosage by determining the mean daily dosage which is required to maintain the critical concentration. Taking the quinine level as $5 \mathrm{mg}$. per liter and the quinacrine level as $25 \mu \mathrm{g}$. per liter, the relative activity of the two is approximately $500 \mathrm{mg}$. $/ 100$ mg.

The general usefulness of plasma drug concentrations in the appraisal of antimalarial activity is emphasized by the data presented. In studies involving a single drug, the plasma concentration of the drug may be considered to be in equilibrium with the concentration at the site of action. In this sense, it is a more reliable datum than the oral dosage, especially with those drugs which are extensively localized in tissues. Furthermore, in the absence of data of this type, it would be diffi- cult to construct rational dosage regimens for the routine management of malaria.

\section{SUM MARY}

The suppressive antimalarial activity of quinacrine has been examined in both vivax and falciparum infections induced by blood inoculation. The data presented describe the relationship between plasma quinacrine concentrations, oral dosage, and the therapeutic results, and define the range of effective plasma quinacrine concentrations in malarial infections due to selected strains of plasmodia. The susceptibility of the erythrocytic phase of malaria to quinacrine action varies with the species and strain of the offending organism. However, the information derived from these studies permits an appraisal of the adequacy of currently recommended dosage schedules for the suppression and treatment of malaria.

\section{BIBLIOGRAPHY}

1. Brodie, B. B., and Udenfriend, S., The estimation of atabrine in biological fluids and tissues. J. Biol. Chem., 1943, 151, 299.

2. Masen, J. M., Quantitative determination of atabrine in blood and urine. J. Biol. Chem., 1943, 148, 529.

3. Shannon, J. A., Earle, D. P., Brodie, B. B., Taggart, J. V., and Berliner, R. W., The pharmacological basis for the rational use of atabrine in the treatment of malaria. J. Pharmacol. \& Exper. Therap., 1944, 81, 307.

4. Shannon, J. A., Earle, D. P., Berliner, R. W., and Taggart, J. V., Studies on the chemotherapy of the human malarias. I. Method for the quantitative assay of suppressive antimalarial action in vivax malaria. J. Clin. Invest., 1948, 27, Suppl., 66.

5. Earle, D. P., Berliner, R. W., Taggart, J. V., Welch, W. J., Zubrod, C. G., Wise, N. B., Chalmers, T. C., Greif, R. L., and Shannon, J. A., Studies on the chemotherapy of the human malarias. II. Method for the quantitative assay of suppressive antimalarial action in falciparum malaria. J. Clin. Invest., 1948, 27, Suppl., 75.

6. Board for the Coordination of Malarial Studies, Quinacrine hydrochloride (atabrine) for malaria. J. A. M. A., 1944, 125, 977. 